\title{
A TABLE TENNIS GLOVE FOR TETRAPLEGICS
}

\author{
By E. R. Slatter, Dip.P.E. and M. M. GibB, R.O.T. \\ Spinal Injuries Unit, Christchurch Hospital, Christchurch, New Zealand
}

Abstract. A new table tennis glove to enable a tetraplegic to hold a table tennis bat is
described and discussed. It is much easier to apply than to bandage the bat to the hand.

Key words: Table tennis glove, Tetraplegics.

\section{Introduction}

THE usual method to enable a tetraplegic to play table tennis is to bandage the bat to the hand. This is well illustrated in a textbook by Sir Ludwig Guttmann. We used this method in our Unit also, but it is time consuming-putting on, taking off and re-rolling the crêpe bandage. We thought there should be an easier way and soon worked out a quick, serviceable method for a tetraplegic to hold the bat in either the right or the left hand.

\section{Construction}

Basically, it is similar to our wheelchair pusher glove, either right- or lefthanded, with an extra wrap-around leather strap, velcro and link-sewn onto the glove at an angle (see Figs I, 2 and 3).

Cost

With the small amount of leather, velcro and two links, the cost is minimal, probably less than Stg $£ 3.50$ including labour.

\section{Adjustments}

It may be necessary to put on a small wrist support splint before the glove, especially so when the tetraplegic has insufficient power in wrist extensions.

\section{Other uses}

We have used this glove successfully with some tetraplegics to hold the bow in archery and the cue for billiards. One of our patients also uses this modified glove for holding a fishing rod and for holding a hand-sanding tool in his home workshop.

\section{Modifications}

Where there is difficulty in wrapping the three fingers around the handle with some tetraplegics it is advisable to build up the handle with Elastoplast or latex rubber, so that the glove will hold the bat firmly.

\section{Practicability}

This method using our glove has now been tried successfully with all tetraplegics who have gone through our Unit in the past 33 months. It is simple, easy 


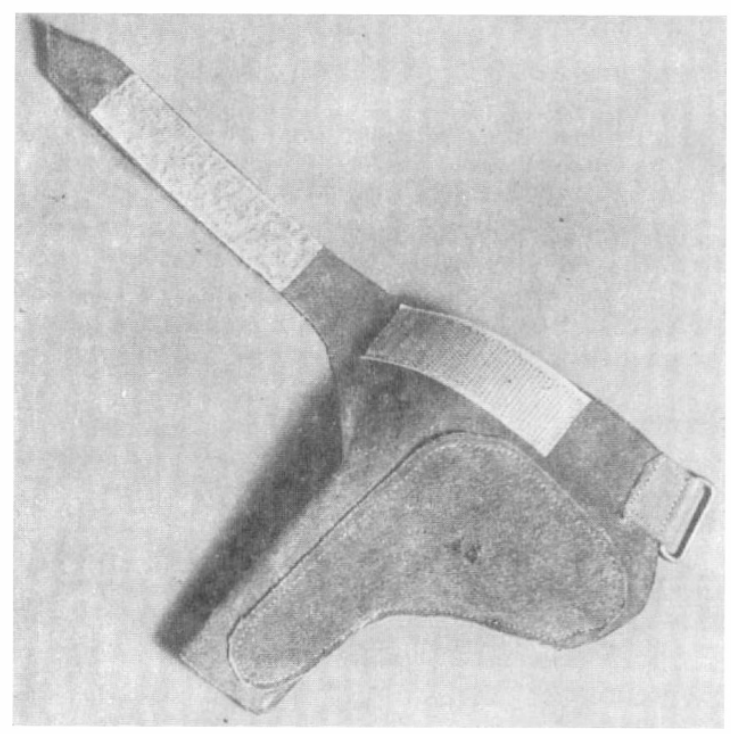

FIG. I

Right-hand wheelchair pusher glove.

FIG. 2

Right-hand table tennis glove.

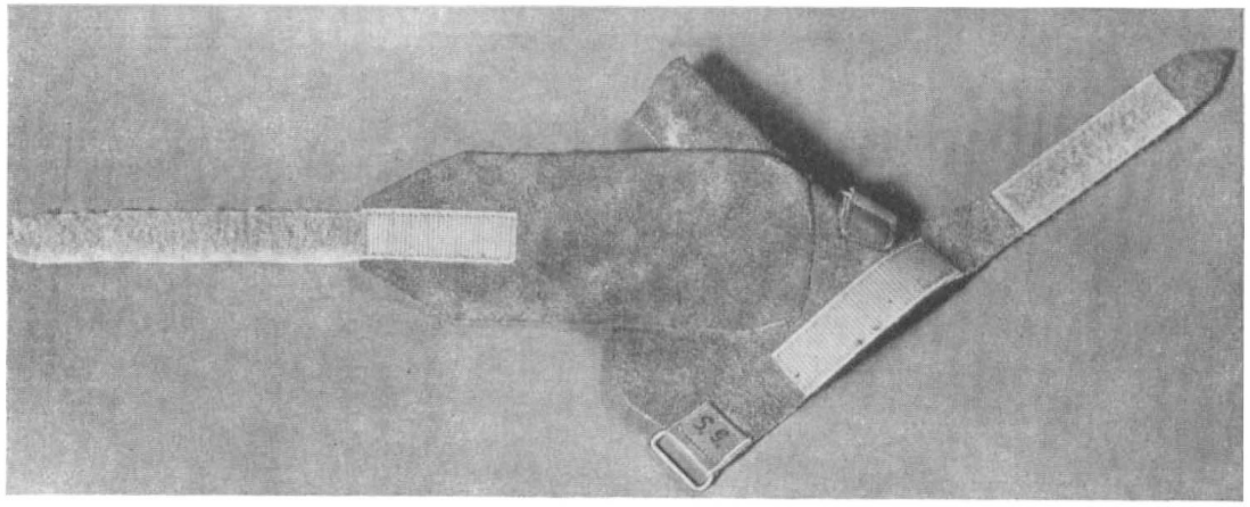

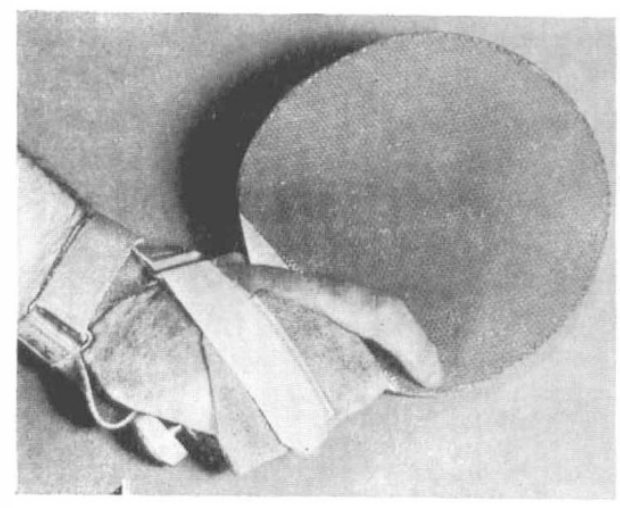

FIG. 3

Right-hand extensor view.

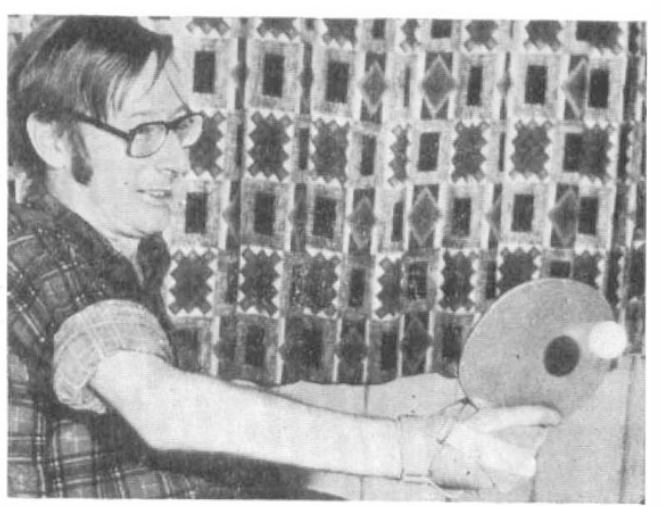

FIG. 4 Tetraplegic playing table tennis. 
to use, less weight to swing around, and we have found no disadvantages at all during nearly 3 years of use.

\section{RÉSUMÉ}

Un nouveau gant pour jouer au Tennis De Table pour les quadriplégiques est décrit et discuté. L'utilisation de ce gant remplace avantageusement l'ancienne méthode qui consiste à attacher la raquette dans la main.

\section{ZUSAMMENFASSUNG}

Eine Beschreibung und Diskussion ueber einen Tisch-Tennis-Handschuh, der einem Querschnittsgelaehmten erlaubt, einen Tisch-Tennis-Schlaeger richtig zu halten. Er ist viel leichter zu tragen als die alte Methode, den Schlaeger an die Hand zu bandagieren.

\section{REFERENCE}

Guttmann, Sir Ludwig (1976). Textbook of Sport for the Disabled, pp. 87 (Fig. 64), 88. H. M. \& M. Publishers Ltd., Aylesbury, Bucks, England.

\section{OBITUARIES}

\section{Dr LORENZ S. Michaelis}

Dr Lorenz S. Michaelis died on 28 February 1979 at the age of 76 after a long illness.

Laury Michaelis studied medicine in Berlin and Breslau and did his M.D. in 1927. From 1927-29 he did pathology at the Rudolph Virchow Krankenhaus and then became Assistant Surgeon in the Department of Orthopaedic Surgery of the University of Breslau under Professor Weil who, after World War II, became Professor Ordinarius of the Orthopaedic Department of Heidelberg University.

Laury emigrated to England in 1935 and after studying medicine in England he obtained the L.R.C.P. (Edinburgh) and M.R.C.S. (Glasgow) in I937. During World War II, he was Orthopaedic Consultant and a member of the Orthopaedic Surgical Unit, Botley from I 942 to 1946, and then Surgeon in Charge of the Orthopaedic Department, Teddington Hospital until 1948. From 1948 to 1950 he worked as S.H.M.O. of the South-West Metropolitan Region and in I950 he joined the National Spinal Injuries Centre, Stoke Mandeville Hospital in Aylesbury at first as S.H.M.O. and in 1966 became one of the Consultants of the Centre.

As an orthopaedic surgeon, he had to adjust himself to many aspects of the complex interdisciplinary specialty of spinal cord injuries and at the same time he was responsible for orthopaedic operations, especially for the treatment of spasticity, which he carried out with great skill. He was a loyal member of the medical team of the Centre and won the respect and love of all his patients. Even after his retirement, he continued his interest and some activities in the Centre. To the editor of Paraplegia he was of immense help in reviewing books.

Michaelis was one of the founder members of the International Medical Society of Paraplegia and took part in discussions on many aspects of paraplegia 